\title{
Trachway video intubating stylet allows for optimization of electromyographic endotracheal tube placement for monitored thyroidectomy
}

\author{
Pi-Ying Chang ${ }^{1}$, Pin-Yang Hu ${ }^{2}$, Yi-Chu Lin ${ }^{3,4}$, Hsiu-Ya Chen ${ }^{2,5}$, Feng-Yu Chiang ${ }^{3,4}$, Che-Wei Wu ${ }^{3,4}$, \\ Gianlorenzo Dionigi ${ }^{6}$ I-Cheng Lu ${ }^{2,7}$
}

${ }^{1}$ Department of Anesthesiology, Kaohsiung Municipal Ta-Tung Hospital, Kaohsiung, Taiwan; ${ }^{2}$ Department of Anesthesiology, ${ }^{3}$ Department of Otorhinolaryngology-Head and Neck Surgery, Kaohsiung Medical University Hospital, Kaohsiung, Taiwan; ${ }^{4}$ Department of Otorhinolaryngology_Head and Neck Surgery, Faculty of Medicine, College of Medicine, Kaohsiung Medical University, Kaohsiung, Taiwan; ${ }^{5}$ Department of Nursing, Kaohsiung Medical University Hospital, Kaohsiung, Taiwan; ${ }^{6}$ Division for Endocrine Surgery, Department of Human Pathology in Adulthood and Childhood "G. Barresi”, University Hospital-Policlinico "G. Martino", University of Messina, Messina, Italy; ${ }^{7}$ Department of Anesthesiology, Faculty of Medicine, Kaohsiung Medical University, Kaohsiung, Taiwan

Contributions: (I) Conception and design: PY Chang, CW Wu, G Dionigi; (II) Administrative support: FY Chiang, IC Lu; (III) Provision of study materials or patients: PY Hu, YC Lin; (IV) Collection and assembly of data: HY Chen; (V) Data analysis and interpretation: PY Chang, IC Lu; (VI) Manuscript writing: All authors; (VII) Final approval of manuscript: All authors.

Correspondence to: I-Cheng Lu, MD. Department of Anesthesiology, Kaohsiung Medical University Hospital, No.100, Tzyou 1st Road, Kaohsiung City 807, Taiwan. Email: u9251112@gmail.com.

Background: Endotracheal tube-based surface electrodes are now commonly applied to measure evoked electromyographic (EMG) response of the vocal cord during monitored thyroidectomy. The aim of the study was to determine the incidence of difficult intubation and to assess the effectiveness of using video-assisted intubating stylet (Trachway) for EMG tube placement in patients undergoing monitored thyroidectomy.

Methods: Medical records were collected from consecutive patients undergoing thyroid surgery before and after implementation of the protocol. A total of 748 patients intubated with EMG tube for monitored thyroidectomy by the same team were enrolled in this study. Patient allocation was based on intubation technique either conventional direct laryngoscopy $(n=336)$ or Trachway $(n=412)$. The intubation difficulty was assessed and analyzed.

Results: The overall incidence of difficult intubation was 4.4\%. Incidence of difficult intubation was significantly lower in patients with the Trachway procedure $(2.7 \%)$ than direct laryngoscopy $(6.5 \%, \mathrm{P}=0.01)$. The incidence of "unable to intubate" ( $>3$ attempts, or change airway device or anesthesiologist) also significantly reduced from $2.3 \%$ to $0.5 \%$ after introduction of the Trachway intubating stylet $(\mathrm{P}=0.02)$.

Conclusions: We conclude that the incidence of difficult intubation was significantly lower with Trachway than direct laryngoscopy. The Trachway video-intubating stylet is useful and helpful to reduce EMG tube intubation difficulty for monitored thyroidectomy.

Keywords: Difficult intubation; thyroid surgery; neuromonitoring; Trachway video intubating stylet; tracheal intubation

Submitted Aug 08, 2017. Accepted for publication Aug 18, 2017.

doi: 10.21037 /gs.2017.08.08

View this article at: http://dx.doi.org/10.21037/gs.2017.08.08 


\section{Introduction}

Intraoperative neuromonitoring of the recurrent laryngeal nerves has obtained growing popularity during thyroid surgery (1-4). The proper placement of the electromyographic (EMG) endotracheal tube is the key point for successful recurrent laryngeal nerve monitoring (5-7). Thyroid surgery may be considered as a risk factor for difficult intubation due to large goiter or cancer. The reported incidence of difficult intubation in thyroid ranges from $5.3 \%$ to $24.6 \%$ higher than in the general population (8-10). If difficult intubation occurs while neuromonitoring is planned for thyroid surgery, an alternative intubation technique might be chosen at the expense of neuromonitoring. For example, airway management without EMG endotracheal tube (such as laryngeal mask airway or nasal intubation) could not be feasible for neuromonitoring. In recent decades, some novel airway management devices such as video-assisted laryngoscope or intubating stylet have been developed to improve the success rate of tracheal intubation and reduce intubation difficulty (11-13).

The Trachway video intubating stylet (Biotronic Instrument Enterprise Ltd., Tai Chung, Taiwan) is a recently developed video-assisted rigid intubating stylet with a distal camera screen. Another proximal light source is mounted on the distal end of the stylet, which has an upward curvature. The Trachway has been reported to be effective in both easy and difficult intubation conditions in both oral and nasal routes (14-16). It was introduced into our neuromonitoring anesthesia protocol to facilitate EMG endotracheal tube placement from 2011. The purpose of this study was to determine the incidence of difficult intubation in patients undergoing thyroid surgery with a neuromonitoring system. Furthermore, we aimed to evaluate the effectiveness of a novel intubation tool (Trachway) in EMG endotracheal tube placement.

\section{Methods}

The study was approved by the Institutional Review Board of Kaohsiung Medical University Hospital (KMUHIRB-E-20150023). Medical records were collected from 748 patients undergoing thyroid surgery with neuromonitoring system between April 2006 and October 2015 in a tertiary medical center. All of them were informed of the protocol to use the neuromonitoring system to aid in the identification and assessment of the recurrent laryngeal nerves function during surgical procedure. All patients were treated by the same surgeon (Feng-Yu Chiang) and an anesthesia team that included two experienced anesthesiologists and one nurse anesthetist experienced in anesthetic care.

From the anesthesia and neuromonitoring records, an experienced nurse anesthetist gathered the data as follows: demographics, ASA physical status, intubation device (laryngoscope, Trachway or fiberoptic bronchoscope), surgical procedure and pathologic reports. Patient allocation was based on intubation technique either direct laryngoscopy $(n=336)$ or Trachway $(n=412)$. The standard anesthesia induction protocol included intravenous anesthetics and a single bolus of neuromuscular blocking agent (NMBA). From April 2006 to December 2010, the placement of EMG endotracheal tube $\left(\mathrm{NIM}^{\circledR}\right.$ Standard EMG Tube, Medtronic, Jacksonville, FL, USA) was routinely done by direct laryngoscopy. The tube was placed with the middle of the exposed electrodes in contact with the true vocal cords under direct visualization. From January 2011 to October 2015, the Trachway video intubating stylet (Trachway) was routinely applied to perform tracheal intubation (Figure 1). All EMG tube positions were further rechecked by fiberscope after successful tracheal intubation.

In the laryngoscope group, difficult intubation was defined as poor glottic view under direct laryngoscopy namely Cormark grade III/IV $(17,18)$. In the Trachway group, difficult intubation was defined when Trachway required extensive manipulated in all directions to identify the vocal cords. Among difficult intubation patients, unable to intubate (extreme difficulty) was defined if there was more than three intubation attempts, or a change in airway device used or a change in person to perform intubation. The classification of tracheal intubation difficulty was assessed by anesthesiologists who performed the anesthesia induction and tracheal intubation. The main outcome was assessed by incidence of difficult intubation. The first attempt success rate and further analysis of difficult intubation were also reported.

All data were expressed as mean (SD). Statistical analysis of continuous variables between groups was compared using the 2-sample $t$-test. Categorical nominal variables were analyzed with the chi-square test or the Fisher exact test. All statistical tests were 2-tailed, and a probability of $\mathrm{P}<0.05$ was considered statistically significant.

\section{Results}

Patient characteristics of both groups are compared in Table 1. Physical status, types of surgery and disease did not differ significantly between the two groups. The overall incidence of difficult intubation was $4.4 \%$ in patients undergoing EMG tube placement for thyroid surgery. The Trachway group showed lower incidence of difficult 


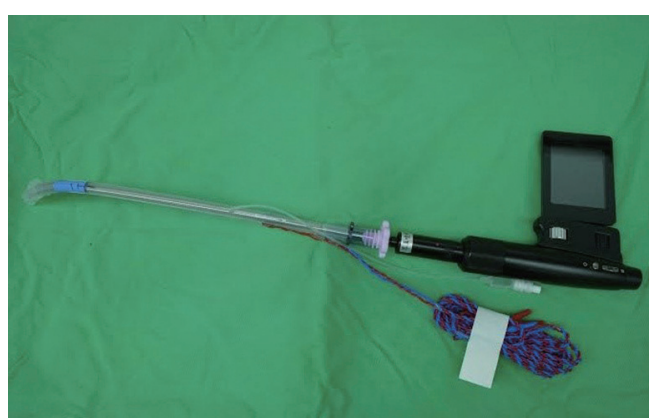

Figure 1 The Trachway intubating stylet loaded with an EMG endotracheal tube. The rigid stylet was lengthened up to a $34-\mathrm{cm}$ fit for the EMG tube. EMG, electromyographic.

Table 1 Patient characteristics between groups

\begin{tabular}{|c|c|c|c|}
\hline Characteristics & Laryngoscope (N=336) & $\begin{array}{c}\text { Trachway } \\
(\mathrm{N}=412)\end{array}$ & $\mathrm{P}$ \\
\hline Age (year) & $50.4 \pm 14.5$ & $50.8 \pm 13.2$ & 0.69 \\
\hline $\begin{array}{l}\text { Gender }(n) \\
\text { Male/female }\end{array}$ & $54 / 282$ & $74 / 338$ & 0.49 \\
\hline BMI $\left(\mathrm{kg} / \mathrm{m}^{2}\right)$ & $24.4 \pm 3.5$ & $25.1 \pm 4.1$ & 0.23 \\
\hline Surgery (n) & & & 0.93 \\
\hline $\begin{array}{l}\text { Total } \\
\text { thyroidectomy }\end{array}$ & $238(70.8 \%)$ & $\begin{array}{c}293 \\
(71.1 \%)\end{array}$ & \\
\hline $\begin{array}{l}\text { Total } \\
\text { lobectomy }\end{array}$ & $98(29.2 \%)$ & $\begin{array}{c}119 \\
(28.9 \%)\end{array}$ & \\
\hline Disease & & & 0.12 \\
\hline Benign goiter & $242(72 \%)$ & $\begin{array}{c}275 \\
(66.7 \%)\end{array}$ & \\
\hline Cancer & $94(28 \%)$ & $\begin{array}{c}137 \\
(33.3 \%)\end{array}$ & \\
\hline
\end{tabular}

intubation $(2.7 \%$ vs. $6.5 \%, \mathrm{P}=0.014)$ and higher success rate of first intubation attempt $(99.0 \%$ vs. $96.4 \%, \mathrm{P}=0.01)$ when compared to the Laryngoscope group (Table 2).

The tracheal intubation was extremely difficult (unable to intubate) in $36 \%(8 / 22)$ and $18 \%(2 / 11)$ of patients within difficult intubation population in the Laryngoscope and the Trachway group respectively $(\mathrm{P}=0.02)$. Overall, the incidence of unable to intubate was significantly reduced from $2.3 \%$ to $0.5 \%$ after introduction of the Trachway intubating stylet $(\mathrm{P}=0.02)$. All 10 patients underwent successful tracheal intubation with an EMG endotracheal tube by alternative methods. Two of them in the Laryngoscope group were
Table 2 Analysis of difficult intubation outcome between groups

\begin{tabular}{llll}
\hline $\begin{array}{l}\text { Intubation } \\
\text { conditions }\end{array}$ & $\begin{array}{l}\text { Laryngoscope } \\
(\mathrm{N}=336)\end{array}$ & $\begin{array}{l}\text { Trachway } \\
(\mathrm{N}=412)\end{array}$ & $\mathrm{P}$ \\
\hline $\begin{array}{l}\text { First attempt } \\
\text { success }\end{array}$ & $324(96.4 \%)$ & $408(99.0 \%)$ & 0.01 \\
$\begin{array}{l}\text { Airway } \\
\text { classification }\end{array}$ & & & 0.01 \\
$\begin{array}{l}\text { Non-difficult } \\
\text { intubation }\end{array}$ & $314(93.5 \%)$ & $401(97.3 \%)$ & \\
$\begin{array}{l}\text { Difficult } \\
\text { intubation }\end{array}$ & $22(6.5 \%)$ & $11(2.7 \%)$ & \\
$\begin{array}{l}\text { Unable to } \\
\text { intubate }(\mathrm{Cl})\end{array}$ & $8(2.3 \%)$ & $2(0.5 \%)$ & 0.02 \\
$\begin{array}{l}\text { Alternative } \\
\text { method for Cl }\end{array}$ & $\begin{array}{l}\text { Fiberoptic } \\
\text { bronchoscopy }(\mathrm{n}=3) ;\end{array}$ & $\begin{array}{l}\text { Laryngoscope } \\
(\mathrm{n}=2)\end{array}$ & \\
& $\begin{array}{l}\text { lightwand }(\mathrm{n}=1) ; \\
\text { trachway }(\mathrm{n}=2) ; \\
\text { change person }(\mathrm{n}=2)\end{array}$ & & \\
\hline
\end{tabular}

intubated via the nasal route with fiberoptic bronchoscopy due to failed attempts via the oral route.

\section{Discussions}

Failure of tracheal intubation is related to catastrophic complications followed by hypoxia and hypoventilation. In operation rooms, the difficulty to intubate occurs in 1.15-3.8\% of population (19). The enlargement of the thyroid gland or cancerous goiter might be associated with tracheal deviation or compression and result in higher incidence of difficult intubation. This study demonstrated that overall incidence of difficult EMG endotracheal tube placement for thyroid surgery was $4.4 \%$, similar to $5.3-5.5 \%$ reported by Bouaggad et al. and Kalezic et al. respectively $(8,10)$ and lower than most reports, that ranged from $8.5-11.1 \%(9,20)$. According to the literature, the reported difficult intubation was the outcome of direct laryngoscopy with Macintosh blade. In this study, difficult intubation occurred in $6.5 \%$ of patients when direct laryngoscopy was used as the routine technique.

The results of this study depicted the significantly reduced difficult intubation incidence from $6.5 \%$ to $2.7 \%$ after the introduction of the Trachway as first-line airway device. Since the clinical application of intubating stylet and video laryngoscopy, these airway devices have improved the success rate, and reduced the difficulty and time of tracheal intubation than conventional direct laryngoscopy technique 
$(13-15,21)$. In a prospective manikin study of new users, where the Trachway was used in both normal and difficult intubation scenarios (11), the intubation success rates for normal and difficult airways were as high as $97.2 \%$ and $95.4 \%$ respectively. The times for successful orotracheal intubation were $11.2 \pm 6.5$ vs. $17.1 \pm 11$. 1 , which is acceptable in clinical settings. Another case series by anesthesiology expertise showed the video laryngoscope (i.e., Glidescope) facilitated optimal position of the EMG endotracheal tube between the vocal cords by visualization on the video screen (22). Other video laryngoscopy such as the McGrath scope or the Pentax airway scope might also allow EMG endotracheal tube placement under real-time video screen confirmation and are deserving of further clinical trials.

The Trachway intubating stylet was chosen as the standard device to place the EMG endotracheal tube for several reasons. Firstly, the Trachway provided better visualization of vocal cords on the video screen compared to other videoassisted airway devices. Then the optimal tube position could be confirmed by fiberoptic examination routinely in our setting. Secondly, the technique without a blade could reduce noxious stimulation during tracheal intubation. Moreover, its rigid stylet within a 7.0 EMG endotracheal tube (outer diameter less than $1 \mathrm{~cm}$ ) allowed airway manipulation even in limited mouth opening scenarios. Finally, the EMG endotracheal tube was about $2 \mathrm{~cm}$ longer than a regular endotracheal tube. The manufactured designed lengthened stylet fit through this specific tube. A drawback of the Trachway was its limited visualization field, which is easily affected by secretion or blood during intubation (11). We found that routinely performed suction before insertion of the Trachway could solve this problem in most situations.

Difficult tracheal intubation is less frequent after the introduction of novel airway devices such as the videolaryngoscope (Glidescope, McGrath, Pentax Airway Scope) and video intubating stylet (Trachway). Limited literature exists concerning airway management when an EMG endotracheal tube failed to intubate. According to difficult airway algorithms, keeping oxygenation and ventilation is the first priority. There are two potential challenges of tracheal intubation for patients undergoing thyroid surgery with neuromonitoring. Firstly, enlargement of the thyroid gland or cancerous goiter might be associated with tracheal deviation or compression and result in difficult intubation. Secondly, both successful intubation and proper EMG endotracheal tube should be achieved for a successful neuromonitoring system.

In two cases with large thyroid cancer in the Laryngoscope group, oral tracheal intubation was impossible by laryngoscopy at initial attempts. A classic laryngeal mask airway could provide adequate oxygenation and ventilation but not is suitable for surgery. Since an EMG endotracheal tube was wider in diameter than a standard endotracheal tube, oral tracheal intubation was chosen to avoid potential nasal trauma. Unfortunately, an EMG endotracheal tube placement via the oral route under fiberoptic bronchoscopic guidance failed again due to oral secretion and poor scope orientation. Fiberoptic nasal intubation could be done successfully with a regular nasal tracheal tube, but could not meet the demand of neuromonitoring. Therefore, these two cases underwent fiberoptic nasal intubation with EMG endotracheal tube after sufficient nasal packing with vasoconstrictor.

One limitation of this study is the retrospective design. Therefore, the comparison of two devices was not blinded and randomized. The degree of neuromuscular blockade at tracheal intubation was not identical for each group. Our clinical practice is to use a single bolus of NMBA and avoid its maintenance dose. The NMBA might be rocuronium or atracurium and dosage ranged from 1 to 2 effective doses. Definition of difficult intubation differs between studies $(9,10,13)$ and some bias of difficult intubation incidence might exist. The intubation difficulty based on evaluation of intubating condition was documented routinely in our practice (23).

\section{Conclusions}

In conclusion, the introduction of the Trachway intubating stylet could reduce the incidence of difficult intubation in patients undergoing thyroid surgery with neuromonitoring. The routine use of a video-assisted airway device is highly suggested for EMG endotracheal intubation. An alternative device should be available for difficult intubation, even though it is rare.

\section{Acknowledgements}

Funding: This study was supported by grants from the Ministry of Science and Technology (MOST 105-2314-B037-010), Taiwan.

\section{Footnote}

Conflicts of Interest: The authors have no conflicts of interest to declare.

Etbical Statement: The study was approved by the Institutional Review Board of Kaohsiung Medical University Hospital (KMUH-IRB-E-20150023). All of 
the patients were informed of the protocol to use the neuromonitoring system to aid in the identification and assessment of the recurrent laryngeal nerves function during surgical procedure.

\section{References}

1. Hermann M, Hellebart C, Freissmuth M. Neuromonitoring in thyroid surgery: prospective evaluation of intraoperative electrophysiological responses for the prediction of recurrent laryngeal nerve injury. Ann Surg 2004;240:9-17.

2. Chiang FY, Lu IC, Kuo WR, et al. The mechanism of recurrent laryngeal nerve injury during thyroid surgery-the application of intraoperative neuromonitoring. Surgery 2008;143:743-9.

3. Chiang FY, Lee KW, Chen HC, et al. Standardization of intraoperative neuromonitoring of recurrent laryngeal nerve in thyroid operation. World J Surg 2010;34:223-9.

4. Sritharan N, Chase M, Kamani D, et al. The vagus nerve, recurrent laryngeal nerve, and external branch of the superior laryngeal nerve have unique latencies allowing for intraoperative documentation of intact neural function during thyroid surgery. Laryngoscope 2015;125:E84-9.

5. Lu IC, Chu KS, Tsai CJ, et al. Optimal depth of NIM EMG endotracheal tube for intraoperative neuromonitoring of the recurrent laryngeal nerve during thyroidectomy. World J Surg 2008;32:1935-9.

6. Randolph GW, Dralle H; International Intraoperative Monitoring Study Group, et al. Electrophysiologic recurrent laryngeal nerve monitoring during thyroid and parathyroid surgery: international standards guideline statement. Laryngoscope 2011;121 Suppl 1:S1-16.

7. Tsai CJ, Tseng KY, Wang FY, et al. Electromyographic endotracheal tube placement during thyroid surgery in neuromonitoring of recurrent laryngeal nerve. Kaohsiung J Med Sci 2011;27:96-101.

8. Bouaggad A, Nejmi SE, Bouderka MA, et al. Prediction of difficult tracheal intubation in thyroid surgery. Anesth Analg 2004;99:603-6, table of contents.

9. Amathieu R, Smail N, Catineau J, et al. Difficult intubation in thyroid surgery: myth or reality? Anesth Analg 2006;103:965-8.

10. Kalezić N, Milosavljević R, Paunović I, et al. The incidence of difficult intubation in 2000 patients undergoing thyroid surgery--a single center expirience. Vojnosanit Pregl 2009;66:377-82.

11. Tseng KY, Chau SW, Su MP, et al. A comparison of Trachway intubating stylet and Airway Scope for tracheal intubation by novice operators: a manikin study. Kaohsiung J Med Sci 2012;28:448-51.

12. Sun DA, Warriner CB, Parsons DG, et al. The GlideScope Video Laryngoscope: randomized clinical trial in 200 patients. Br J Anaesth 2005;94:381-4.

13. Nouruzi-Sedeh P, Schumann M, Groeben H. Laryngoscopy via Macintosh blade versus GlideScope: success rate and time for endotracheal intubation in untrained medical personnel. Anesthesiology 2009;110:32-7.

14. Cheng WC, Lan CH, Lai HY. The Clarus Video System (Trachway) intubating stylet for awake intubation. Anaesthesia 2011;66:1178-80.

15. Hung KC. A novel modified method of using Trachway intubating stylet for awake tracheal intubation in patients with anticipated difficult airway. Acta Anaesthesiol Taiwan 2013;51:90-3.

16. Lee MC, Tseng KY, Shen YC, et al. Nasotracheal intubation in patients with limited mouth opening: a comparison between fibreoptic intubation and the Trachway®. Anaesthesia 2016;71:31-8.

17. Cormack RS, Lehane J. Difficult tracheal intubation in obstetrics. Anaesthesia 1984;39:1105-11.

18. Koh LK, Kong CE, Ip-Yam PC. The modified CormackLehane score for the grading of direct laryngoscopy: evaluation in the Asian population. Anaesth Intensive Care 2002;30:48-51.

19. Walsh K, Cummins F. Difficult airway equipment in departments of emergency medicine in Ireland: results of a national survey. Eur J Anaesthesiol 2004;21:128-31.

20. Voyagis GS, Kyriakos KP. The effect of goiter on endotracheal intubation. Anesth Analg 1997;84:611-2.

21. Griesdale DE, Liu D, McKinney J, et al. Glidescope ${ }^{\circledR}$ video-laryngoscopy versus direct laryngoscopy for endotracheal intubation: a systematic review and metaanalysis. Can J Anaesth 2012;59:41-52.

22. Berkow L, Dackiw AP, Tufano RP. Use of the GlideScope for placement of a recurrent laryngeal nerve monitoring endotracheal tube. J Clin Anesth 2011;23:81-3.

23. Fuchs-Buder T, Claudius C, Skovgaard LT, et al. Good clinical research practice in pharmacodynamic studies of neuromuscular blocking agents. II. The Stockholm revision. Acta Anaesthesiol Scand 2007;51:789-808.

Cite this article as: Chang PY, Hu PY, Lin YC, Chen HY, Chiang FY, Wu CW, Dionigi G, Lu IC. Trachway video intubating stylet allows for optimization of electromyographic endotracheal tube placement for monitored thyroidectomy. Gland Surg 2017;6(5):464-468. doi: 10.21037/gs.2017.08.08 